
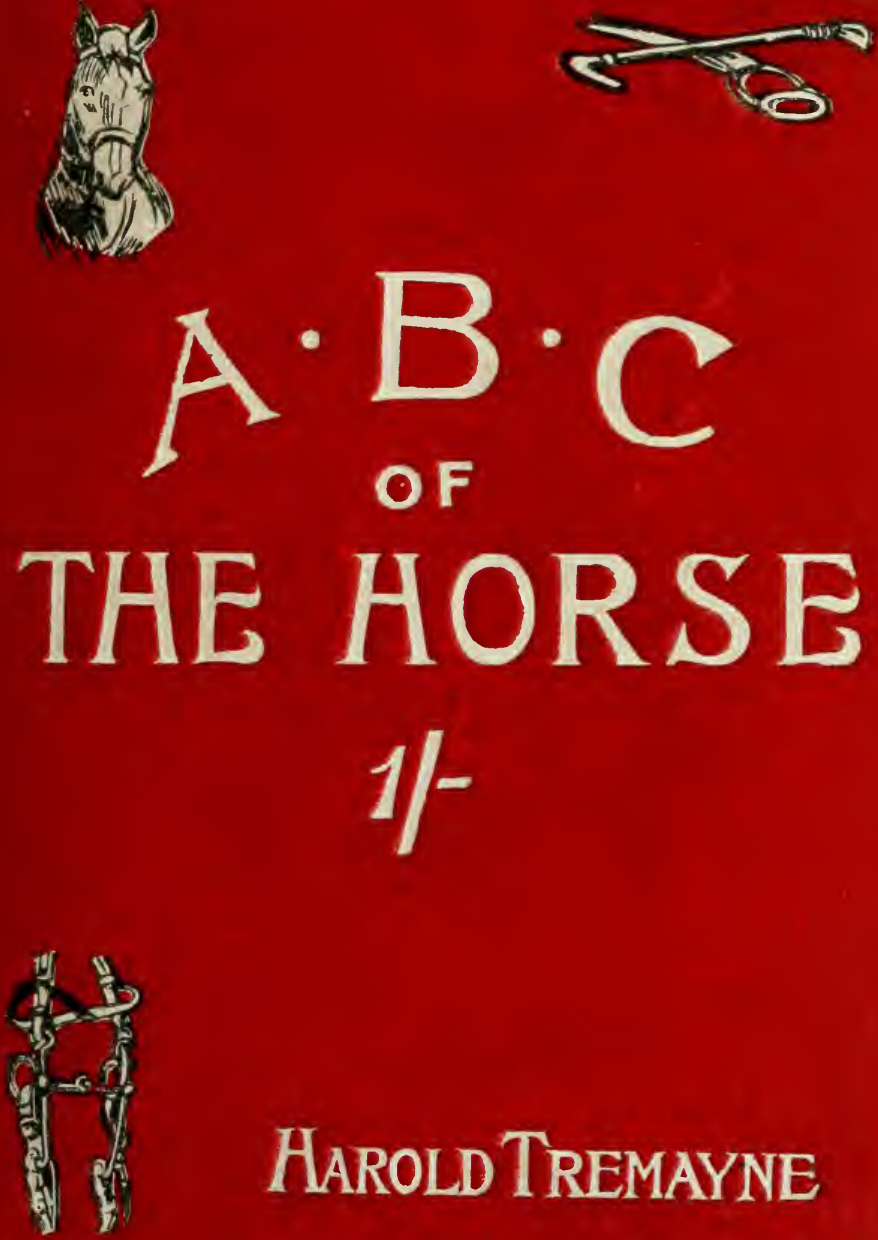

\title{
Harold Tremayne
}




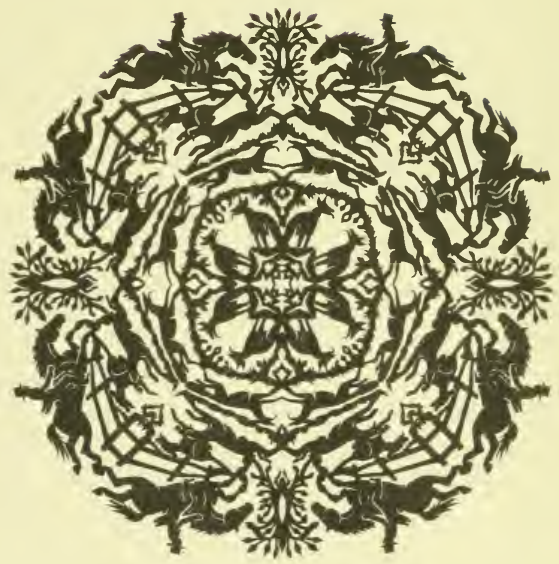

JOHN A.SEAVERNS 


\section{DRANE'S WELL=KNOWN \\ ONE \\ SHILLING

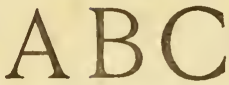 \\ HANDBOOKS \\ As easy as $\mathbf{A} \mathbf{B} \mathbf{C}$ \\ Red Cloth White Foil Lettering}

A NEW series of small, attractively printed and bound volumes, which will go in the pocket. Written by Specialists, they will be found to contain all worth knowing about the different subjects upon which they treat, and yet so clearly and plainly written that all who read will understand.

1.-The A B C of Bridge. By E. A. Tennant. Description and Rules of the Game. How to Score. How to Play. What to Lead, etc. "We have not met a better guide."-Saturday Review.

2.- The A B C of Photography. By E. J. WALL, F.R.P.S. Containing instructions for making your own Appliances, and simple practical directions for every branch of Photographic work. Illustrated and up-to-date.

3.-The A B C of Palmistry; or Character and Fortune Revealed by the Reading of the Hand. By a well-known Palmist. With 12 full-page illustrations.

4.-The A B C of Physiognomy; or How to Tell your Neighbour's Character by Reading His or Her Face. By Paul Bello. With 6 fullpage illustrations.

5.-The A B C of Graphology. A Dictionary of Handwriting and Character. By WVENTwORTH BENNETT. With I7O illustrations. 


\section{DRANE'S A B C HANDBOOKS-continued}

6.-The A B C of Dancing. A Book of useful information and genuine Hints for Dancers and Learners. By EDWARD SCOTT.

7.-The A B C of Solo Whist. By Edwin Oliver. Description and Rules of the Game. How to Score. How to Play. What t oLead, etc.

8.-The A B C of Table Tennis. By C. G. Eames. Telling all there is to be told on Table Tennis or Ping Pong. Rules. Style of Play, etc.

9.-The A B C of Housekeeping. A Guide to all Housekeepers. What to do and How to Keep a House in Order. By J. N. BeLL.

10.-The A B C of Swimming. This book will teach anyone who can read How to Swim in Five Minutes. By an ex-Captain of a London Swimming Club.

11.-The A B C of Gardening. What to Sow or Plant, and How to Grow it in a Window Box, Greenhouse, Cottage, Villa, or Roof Garden. Everything made as simple as A B C. By a Practical Gardener.

12.-The A B C of Motoring. By C. W. Brown. 13. -The A B C of Bird Keeping. By W. Percival Westell.

14.-The A B C of Invalid Cookery. By Mrs, KIDDLE.

15.-The A B C of Carpentry. By Geo Day. 16.-The ABC of The Dog. By HAROLD TREMAYNE. 
Gerliude Toldsinid Fob. 1907

THE ABC OF THE HORSE 
. 

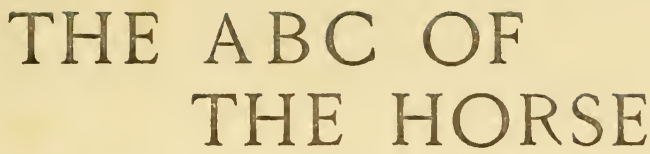

HOW TO BUY, HOW TO TELL AGE, MANAGEMENT, FRAUDULENT PRACTICES, AILMENTS, TREATMENT, Etc., Etc.

\section{BY \\ HAROLD TREMAYNE}

AUTHOR OF

" REMINISCENCES OF A GENTLEMAN HORSE DEALER," ITC., ETC.

LONDON H E N R Y J. D R A N E (YE OLDE ST. BRIDE'S PRESSE) * SAlisbURY hOUSE SALISBURY SQUARE * FLEET STREET, E.C. 


\section{Printed by Henry J. Drane, Ye Olde Saint Bride's Presse, Salisbury Square, London, E.C.}




\section{CONTENTS}

PAGE

PREFACE · $\cdot \cdot \cdot \cdot$

Different Breeds OF Horses - The Difficulty of Selection • • • I I

CHAPTER II

How to Buy a Horse - Fraudulent Practices to be Guarded Against . 36

\section{CHAPTER III}

How to Tell the Age of tile Horse. 64

\section{CHAPTER IV}

General Management : GroomingSTABLING-FEEdING • • . • 70

\section{CHAPTER V}

Minor ACcidents AND Ailments, AND THEIR TREatMent 


\section{BY THE SAME AUTHOR}

\section{ALL YOU WANT TO KNOW ABOUT THE DOG}

THE . . .
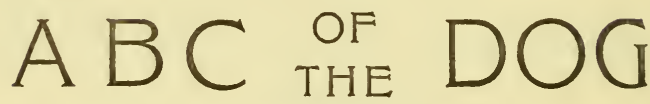

How to Choose a Dog, How to Train a Dog. The Ailments of the Dog and their Treatment, How to Buy a Dog, etc, etc.

\section{$\mathrm{BY}$ \\ HAROLD TREMAYNE}

\section{Price}

One Shilling

\author{
Price \\ One Shilling
}

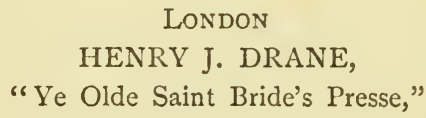

Salisbury House, Salisbury Square, E.C.

If you have any diffculty in obtaining the above Book, the Publisher will be pleased to forward, post free, on receipt of published price. 


\section{PREFACE}

THE little book, which now makes its bow to the public, has not any pretentious aims. It is not intended as a competitor with the large and serious works which have of late years placed such a fund of valuable information at the disposal of the lover of the equine race. The $A B C$ of the Horse merely seeks to render a little help to the man who keeps one, or, it may be two horses for pleasure, and who whilst desirous for the well-being of his animals, has not the time, or perhaps the inclination, to wade through a large and technical volume. I do not for one moment profess to say anything new in the book, but merely to give the owner an opportunity of learning sufficient to prevent a display of ignorance in the presence of the groom he employs, the dealer he may be buying from, 
or the "horsey" friend whom he may be showing over his stable. The veterinary section also asks for the same modest understanding. Simple ailments are only dealt with, for if the capability to realise their presence is learnt and appreciated, then there will be but little danger of the graver troubles being overlooked. With this explanation I put down my pen, feeling that the very unpretentiousness of the volume will earn the kindly consideration of the critics, and that I may have perhaps done a little to help the animal for whom no man hath greater love than has

HAROLD TREMAYNE. 


\section{The A B C of the Horse}

\section{CHAPTER I}

DIFFERENT BREEDS OF HORSES-THE DIFFICULTY OF SELECTION

IN an elementary work, such as this only professes to be, it is impossible to deal at length with the numerous breeds of horses which are to be found in the British Isles, and the necessity for such a course is nullified by the knowledge that the reader of 
this book is hardly likely to be a purchaser of other than a specimen of a "light breed." Then again, it is impossible in the space at disposal to deal with the history of those breeds, or to trace, say, the effect which the introduction of Arabian blood by James I. and Charles I. has had upon the thoroughbred. Such information, valuable although it is to the student, would be out of place here, for it is with present-day requirements rather than the particulars furnished by that valuable work, the Stud Book, which we have to consider.

When the tyro decides that he will 


$$
\text { A B C OF THE HORSE }
$$

find an occupant for his stable, he is confronted with the question-" "What sort of animal should I keep?" It is obvious that the man who wishes to travel, say, a mile and a half to the station every morning in the shortest possible space of time, will choose a different class of animal to him who desires something which will make envious neighbours forget the injunction of the Tenth Commandment, and declare-" "What a splendid animal! What magnificent action!" The horse which is intended for show, which is wanted for a stylish equipage, must necessarily be a trifle 
"above itself" in condition, and although pace and action are by no means incompatible, experience goes to show that the animal which is continually driven at a fast pace invariably loses a great deal of its action. This fact is proved by a visit to the showyards. The horses which turn up again and again as winners are those which are in high condition, and it will be noticed that they are always driven in a collected manner. "Pace brings down the knee action" is an old stable saying, which, unlike some sayings emanating from the same quarter, is perfectly true. 
The difficulty of selection of a type of animal is to the novice undoubtedly great. The first question, however, which he should put to himself is, "What do I require the animal for?" That question should be carefully considered before any step is taken, as otherwise it is more than likely that dissatisfaction will result from what was a wrong move in the first place. If he wants a hack, he will look for a different class of animal -certainly a different type of shoulder -to what he would seek in a trapper, whilst if he wants a general utility horse-that is to say, one capable of 
being ridden or driven-he will look for the "useful stamp," which, although not likely to make such heavy inroads on his banker's balance, should, if once secured, be not parted with lightly. The general utility horse, which can be relied upon to go well and quietly, either between the shafts or under saddle, is invaluable, although his appearance may not be so stylish as that of his more favoured brother or sister who is kept for one purpose only. Between I5.I hands and I5.3 hands is a useful height. If an animal is above 15.3 he requires a large or high carriage, and of late years fashion 


$$
\text { A BC OF THE HORSE }
$$

has rather favoured the medium-height trap.

Cobs are very popular with the "one-horse keeper." Although the term "cob" is perhaps a trifle ambiguous, it is generally applied to any animal between I4.I hands and I 5.I hands. This statement may perhaps be challenged by the equine authority, who will triumphantly ask, "How can a cob be anything between I4. I hands and I5.I hands, when a polo pony is allowed to measure 14.2 hands?" This argument can only be met with the reply that $\mathrm{I} 4.2$ hands is the extreme limit of height of the 
polo pony, and that that limit, although doubtless fixed in the best interests of the game, certainly exceeds that of any specimen of the mountain breeds of ponies to which we have in the past looked for our best specimens.

The pony has of recent years come in for a wonderful share of popular favour, and when all the circumstances are considered, the fact is not surprising. This animal is capable of an enormous amount of work on very short commons. Although he shows the benefit of a plentiful supply of good food, the pony can rub along 


$$
\text { A B C OF THE HORSE }
$$

where many specimens of the large race would soon go to the wall. $\mathrm{He}$ is also wonderfuily hardy and strong. Long journeys seem to agree with his constitution, and his capacity to rough it is of no little value to the "one-horse," or, rather, "one-pony owner," who finds other work beside the stable for the man employed about the place. The value of the pony is shown by the increased prices he commands. Every year the supply is increasing, the fact that there is money in pony breeding being more and more recognised, but nevertheless prices show an upward tendency, and 
when a really good specimen comes under the hammer, the heads of prospective buyers nod with prompt regularity. The I4 - hands pony makes an excellent hack if the action is all right, but the prospective buyer must not fail to bear in mind the weight which the animal may be called upon to carry. The man who rides, say, fifteen or sixteen stone, would in all probability do better to choose a stout general utility cob of I4. 3 hands.

These points must be carefully borne in mind before the purchase is made. What is the animal wanted for? 


$$
\text { A B C OF THE HORSE }
$$

What size and type of carriage is it required to draw? Who are likely to be the drivers or the riders? Are those drivers or riders inexperienced or nervous? for it must not be forgotten that intuition quickly tells the steed who is holding the reins, and the horse or pony which is perfectly quiet with one man, may, through excessive spirits or a spice of mischievousness, behave very differently with another person. To pursue the questions, however-How much work is required to be done? What is the pace at which the owner wishes to travel? And lastly, 
but perhaps by no means least, What amount of attention is it proposed to bestow on the animal? This question must not be taken as suggesting that certain animals can do with but little attention. Such an idea is very far from the mind of the writer. No horse or pony can thrive, or do its owner or itself justice, if it be neglected, for its health, and, consequently, its physical capacity, is bound to suffer, but, on the other hand, the horse which is required to do its six miles in half an hour requires somewhat different food and attention to his brother who is 
taken in from the paddock to comfortably trot a similar distance in double the time.

In concluding this chapter perhaps the best thing to do would be to give a few particulars of the leading breeds and the types they represent.

The Cob.-As previously mentioned the cob has of late years been taken wonderfully into popular favour. The variation in price is remarkable. Animals possessing excellent points can frequently be picked up for twenty pounds or twenty-five pounds, whilst, on the other hand, a really first-class Park cob, that is, an animal which 
has good all-round action in a trap, or an animal which is perfect in its pacos and quiet for the most nervous old gentleman to ride, will command a very big figure. A typical cob should have a round barrel and quarters, and short, muscular, flat limbs. The neck should be short and muscular, and should be joined to well-sloping shoulders, with that graccful line which denotes strength and good breeding. The knees should be broad and flat, whilst the hocks should denote strength without coarseness. The hind legs should not be set on too far behind, so 
as to be what is known as "camped," for then there will be a loss of power and an unpleasantness of action.

\section{The Hackney.-Probably the Hackney} is the most popular of all the light breeds, and the reason is not far to seek. Wealthy men have for many years now been lavishing moncy on him, until they have produced as fine specimens of horse flesh as man could desire to see. It is claimed by admirers of the breed that a Hackney is a general utility horse, and that he cannot be put in a place where he will not acquit himself 
well. The writer, however, dares to hold a different view. Although an ardent admirer of the Hackney as a harness horse, I venture to state that my own experience goes to show that that animal is not the best that can be chosen when a saddle horse is also required. The very magnificence of the action of the Hackney makes against him as a comfortable carrier of a rider, but having said this I must hasten to urge his enormous merits for harness purposes. The typical Hackney possesses a face of striking intelligence, the full, kind eye at once arresting attention. The 
chest should be deep and wide, the body short, the ribs well sprung, the loins powerful, whilst the limbs should display strength without coarseness. Strong arguments in favour of the Hackney are that he generally possesses plenty of courage, good temper, and excellent feet and legs. A badtempered Hackney is a rara avis, and although detractors of the breed have often urged the charge of "softness of constitution," experience goes to show that the Hackney is capable of doing an enormous amount of work without showing the effects of it. Prices vary considerably. Prize 
winners, or mares by well-known winners fetch large prices, but it is possible to obtain a very fair animal for anything from forty-five pounds to eighty pounds.

The Hunter.-During recent years the thoroughbred has become the popular mount in the grass counties of Leicestershire, Northamptonshire, etc., the reason being that the increased pace at which hounds travel nowadays makes it necessary for a horse to be able to gallop and jump at a tremendous rate. It is frequently affirmed that the thoroughbred is the horse for any and every county 
but, as a matter of fact, in a close county, that is, where there is more ploughed land, and the enclosures are smaller, the half-bred hunter is generally preferred. A typical hunter should be absolutely sound in wind and eyesight. The head should be lean and the neck moderately long. Good oblique shoulders, prominent withers, strong back and loins, well-sprung ribs, wide hips, and muscular thighs, should top powerful legs and sound feet. The hocks should be particularly strong, for upon them is thrown the chief portion of the work whenever a leap is under- 
taken. In fact, a hunter should show power all over, without that coarseness which is a sign of inferior breeding. It is impossible to name the price usually paid for a hunter. A great deal depends on the weight of the rider, and also upon his skill with animals. A light-weight, that is to say, a man who can ride ten stone, can, if he knows his way about, fill his stable with thoroughbred "weeds," upon which he may see a great deal of sport, for thirty pounds or forty pounds apiece, whilst the man who rides sixteen or seventeen stone may find it difficult to satisfy 
his requirements for less than ten times those sums.

The Pony.-A tribute of praise was paid to the pony in an earlier portion of this chapter. The best known breeds are the Dartmoor, the Exmoor, the New Forest, the Shetland, and the Welsh ponies. Unfortunately, too little attention was paid to these breeds for many years, consequently the result of neglect in mating is now but too apparent. There has, however, recently been a change for the better; societies for their preservation and improvement have sprung into existence, and it is to be hoped that in the near 
future the good points which have in too many cases been allowed to disappear, will be resuscitated, and that true specimens of the breeds will be placed on the market at prices not prohibitive to the man with a limited income. The size of the Shetland pony necessarily renders it unsuitable for any but small children, but with regard to the other breeds, although they all possess certain distinguishing features, it naturally follows that ponies must necessarily possess certain points of similarity in common. The pony should be similar in conformation to the cob-in fact, he should be a 
"miniature cob." It will be usually found that the legs and feet of the mountain-bred pony are good, the very nature of his early existence making for surefootedness and strength. The prices vary considerably. Dartmoor ponies can be purchased as yearlings for five pounds or six pounds, whilst the "made article," that is, the five-year old pony, quiet to ride and drive, will fetch anything, according to its appearance and action.

The Roadster or General Utility Horse may consist of any breed of horse at all, or of any of the breeds crossed. It would be waste of space $\mathrm{c}$ 
to attempt to recapitulate here the points which should be looked for, as of course, the question, "What is the animal wanted for?" must play the leading part in the decision arrived at. Taken generally, however, the man who buys a half-bred, and who bears in his mind's eye the description given of a cob and a hackney, will not go far wrong. In the roadster, soundness and strength of limbs and feet should be a sine qua non, for the horse which does not possess these essentials, is likely to damage himself and his driver or rider down the first hill he goes. The general utility horse can be bought for any- 


\section{A B C OF THE HORSE}

thing from thirty pounds to sixty pounds, although perhaps it would be safe to say that the average price is about forty-five pounds. 


\section{H A P T E R II}

HOW TO BUY A HORSE-FRAUDULENT PRACTICES TO BE GUARDED

\section{AGAINST}

IT is perhaps one of the hardest things in the world to tell a man how he should buy a horse. It is easy to fill pages of a book with good advice as to what faults should be looked for, what good points should be essential, but even if the prospective buyer carried all the text-books on the subject to the place where he was to see the animal under consideration, and 36 


\section{A B C OF THE HORSE}

even if he read every word of that advice, glancing the while at the steed, if the text-book student had not had previous experience, if he had not a natural gift for finding and appreciating the good or bad points, then the probabilities would be that he would err in some little detail. Buying a horse has been declared to be as difficult as the choice of a wife, and although this may in some degree be true, it is perfectly certain that whilst the dissatisfied purchaser can always send the horse to the nearest repository, the dissatisfied husband must-but why pursue the subject further? 
There are, of course, numerous ways of purchasing a horse. The buyer may attend a local fair, and relying upon his own judgment choose an animal which seems to meet his requirements. This is a difficult task for even the most experienced to undertake. A large number of the horses which find their way to fairs do so because they have some fault or vice which reduces their value. This statement must not be taken in too sweeping a sense. Scores of horses, especially those sent from Ireland, are perfectly sound and well worth the money paid for them, but in a general way it may be 


\section{A B C OF THE HORSE}

safely assumed that the animals which are at all worth the money asked are quickly snapped up by the dealers and their representatives. Usually the fairs are the resort of either young, partially broken horses, which are excellent material for "experience" to work upon, or else of aged horses for whom it is difficult to find a market. The very excitement of a fair is a cloak to the faults which are not easily discernible. In fact, it may be safely assumed that for a novice to purchase a horse of his own selection at a fair, or in one of the repositories which abound in all the big towns, is like putting the 
hand into a lucky dip where the blanks considerably exceed the prizes.

If the purchaser be determined to buy in either of these places he should have for his companion a veterinary surgeon or a friend upon whose judgment he can rely. Even then the possibilities of a bad bargain are by no means remote. The veterinary surgeon can, of course, tell if the animal has any physical defect, but it is impossible in a short examination to prophesy what will be the horse's behaviour between shafts or under saddle. Frequently the statement appears in a catalogue-"Has been 


\section{A B C OF THE HORSE}

ridden and driven by a lady," or "Has been ridden by a child." To the novice this information would seem sufficient for all purposes, but men who have been in the trade will not hesitate to say that there are plenty of women who can and do ride and drive animals which a great many men would hesitate to tackle, whilst the writer has a little friend, a boy of eleven years-therefore well within the description "Has been ridden by a child "-who will sit anything pretty well that has ever been foaled. Not so very long ago this young hopeful had a twenty-minutes' tussle with as bad tempered a thorough- 
bred as any man would desire to see in his stable, and when the plunging, kicking, bucking mass of vitality had exhausted his energies, the perspiring youngster slid out of the saddle, remarking, "I have ridden quieter horses than that one, father." This illustration is furnished in order to demonstrate the necessity for a certain amount of reservation in the acceptance of catalogue descriptions. Of course, it may be said that if an animal does not come up to the warranty it can be returned. True! But what warranty is there in the statement "Has been ridden by a child," or, "Has been ridden and driven by a lady"? 


$$
\text { A B C OF THE HORSE }
$$

There are two ways of purchasing animals which seem to reduce the risk to a minimum. The first is buying from a reputable dealer, and the second is entering into negotiations with a bonafide advertiser in one of the high-class agricultural journals. In both these cases the purchaser has ample time to consider and weigh the information which is offered him. When a gentleman is anxious to sell a horse, he will frequently allow it to go on a week's trial, especially if the prospective purchaser agrees to pay a small sum if a deal is not effected. A large number of dealers will also allow an animal to 
go on trial for a week or a fortnight, if fair payment for hire, in the event of its return, be guaranteed. The horse which the dealer would not allow to leave his stable on these terms should be viewed with a certain amount of suspicion, This may sound a sweeping statement, and undoubtedly there are many dealers who do not like the "trial system," but as a rule a dealer will give way rather than lose a customer. Of course, when the horse is in your own stable, and away from the eye which jealously guards him from the danger of obviously betraying any little failing, which, whilst not amounting to a defect may, nevertheless, 


\section{A B C OF THE HORSE}

militate against the chances of a deal, your opportunity for a careful and prolonged examination is all that you could possibly desire. Take advantage of that opportunity, for it is not fair on the dealer who has given you a week's trial to go back to him a month later and complain about some defect which should have been obvious long before.

We will suppose, however, that the prospective buyer is visiting a dealer's stable for the purpose of purchasing a horse, and he is shown one, which, as far as general build goes, meets his requirements.

Now the process of careful examina- 
tion should be proceeded with. This can be done by the novice himself, even if he has the assistance, which, of course, he should have, of a veterinary surgeon or an experienced friend, for the old adage "Two heads are better than one" is applicable to horse buying. Whilst the horse is in the stable his general behaviour should be carefully watched. On no account should an officious groom be allowed to go to its head with an exhortation to "Get up," for the natural pose should be one of the first things to be observed. The front legs should be looked at to see if the animal "points" or not. "Pointing," 
as it is known in stable parlance, is standing with the lame leg flexed. Horses with slight lameness will frequently point, or when they have incipient trouble with the feet or legs, the first indication is a flexing of the afflicted limb. Such stable vices as cribbiting, weaving, wind sucking, shivering, scraping, and resting one hind foot upon the other are most easily discerned when the animal is standing perfectly quiet. It is as well, perhaps, whilst the horse is in the stable, and its feet are clean, to go up alongside of it and examine them. See that the frog of each foot is perfectly clean and sound, 
and that it does not smell. If there is any unpleasant smell arising from the sole it may be safely assumed that the animal is suffering from thrush, which is a difficult disease to cure, and which, if not taken in time, soon plays havoc with the foot. The heels should be open, and in no ways contracted. Look also for sandcrack, but perhaps it would be as well to reserve a more detailed examination of the foot until the animal is outside in the broad glare of daylight. When the horse has been taken outside the stable, let it be slowly trotted upon hard ground. Lameness, if present, will then be apparent; and as a 


\section{A B C OF THE HORSE}

general rule when an animal is lame behind, the disease is in the hock, and when in front in the suspensory ligaments of those horses used for fast work. In his interesting work, Veterinary Notes, Captain Hayes says: "When a horse goes lame on a fore leg without any perceptible cause, and wears away the toe of the shoe, we may suspect that foot of navicular disease. But if he goes on the heel, the probability is that he has either laminitis, . 'seedy toe,' or incipient ring bone. If the lameness be behind, and the toe of the shoe becomes worn, we shall generally find that it is due to spavin. 
50 A B C OF THE HORSE

Side-bones are almost peculiar to cart horses, sore shins to race-horses, and navicular disease to riding, $\mathrm{cab}$ and carriage horses. Navicular disease and occult spavin are hardly ever found in horses under seven years of age."

Intermittent lameness may be caused by rheumatism, whilst it is well to bear in mind the fact that in many cases lameness disappears with exercise. The prospective buyer should therefore watch very carefully the animal's movements from the time that it leaves the stable, for the more it gets warmed by its exercise the less likely are the chances of detecting defects. 


$$
\text { A B C OF THE HORSE }
$$

Having satisfied himself as to the soundness of the action of the animal, the buyer should proceed with his examination in detail. The general conformation should be carefully studied from the front so that any wasting at the shoulder, narrowness of the chest, or turning in or out of the toes could be observed. Coming around to the near side, the general shape of the body, and the position of the fore and hind limbs, should be noted. A flat-sided animal will never do its food justice, whilst unless the legs are set on properly it cannot carry itself or its rider safely. Horses with 
twisted fore-legs are apt to hit the inside of the fetlock joint, and under the knee as well. Moving on, the observer now takes his stand behind the animal, and he should carefully note the space between the hocks, and also the general shape of those joints. Capped hocks can be observed from this position. They are unsightly, and are frequently caused by kicking, but they very seldom cause lameness. Passing around to the off-side, the observer pursues his examination. All this of course takes time, which although perhaps irritating to the vendor is not without use to the 
purchaser. The manner in which the animal submits to the ordeal is some little guide as to its temperament. If, for instance, whilst standing behind it, the animal lashes out with its hind legs, as I have seen horses do more than once, then the examination can be promptly concluded, for its temperament is hardly likely to suit the "onehorse" owner.

Having concluded the ocular inspection the horse should be handled in order to find any of those defects which may not be apparent to the naked eye. The teeth should be examined for signs of crib-biting 
disease, and fraudulent practices-which are dealt with later on-the nostrils for the general tone of health, the eyes for cataract or other disease, and the poll for what is known as "poll-evil." Then, moving around to the near or left side an examination should be made of the jugular groove, in order to see if there are any scars-fairly sure signs that the horse has been bled. It may be mentioned here that those scars are not so frequently met with nowadays as they were thirty years ago, when bleeding was "the rage." Where the collar presses should be carefully examined for signs of galling, and 
whilst referring to that matter, it would be perhaps as well to point out the necessity of examining the withers for fistula, and the "saddle-bed" for galls. If old marks only are found it is perhaps well not to pay too much attention to them, as they are generally caused by an ill-fitting saddle, a thing which we presume the reader of this work would not tolerate for one moment. Having concluded the examination of the shoulders and withers, the hand should be run down the near fore-leg for the purpose of detecting any blemish or any bony deposit-known as a splint-between the knee and the 
fetlock, or any thickening of the flexor tendons or of the suspensory ligament. The position of a splint decides its importance. If it be near a joint, or likely to involve a joint, then it is a grave defect, but otherwise veterinary surgeons do not attach much importance to it. On the other hand, any thickening of the flexor tendons and of the suspensory ligament is very serious, and should ensure the rejection of the animal. Having examined the leg to see that the operation known as "neurotomy" has not been performed, the knee or fetlock joints should be flexed, as any stiffness about either of 
these joints is very objectionable. A further examination of the foot should then be made in order to see if there are any laminitic rings upon the hoof wall, and the hoof should be tapped for corns. If any be present the animal will flinch and exhibit other signs of uneasiness. The near hind leg next comes in for examination. Wasting of the muscles over the stifle should be looked for, and then a careful examination of the hock should be made. Stiffness of the joint can be discovered by flexing it, whilst an examination by the hand, and comparison between the two hocks, should help the observer in 
arriving at a decision as to their condition. If the slightest difference in appearance be noted, the reason should be carefully searched for. Spavins, which are somewhat similar to splints, except that they occur in the hock only, show themselves on the inner side of that joint, just below the bend. Spavin is very evident when the animal first leaves its stable.

Curbs occur a few inches below the point of the hock, and although they frequently do not cause lameness, they undoubtedly constitute unsoundness. Having run the hand down the cannon bone, and found it clean and cool to 


$$
\text { A B C OF THE HORSE }
$$

the touch, the hoof and sole are carefully examined. Then the observer passes around to the offside, and repeats on the off fore and hind legs the task he has performed on the near fore and hind legs. This being concluded, the only thing which remains to be done is to test the animal's wind. This is best done by having it smartly galloped on a soft, and, if possible, heavy piece of ground, or by having it put in a carriage, if a harness horse, and driven rapidly up a moderately steep hill. Another method of testing the wind is to place the animal against a wall and suddenly raise the hand as 
if to strike it. If it emits a grunting sound the liveliest suspicions should be aroused, and a further test proceeded with. As previously stated, the above directions for the examination of a horse are merely intended for the amateur. The "expert," by whom such an amateur should always be accompanied, would probably make a much more detailed examination, but such details would be far too technical for the compass of the present work. Fraudulent Practices.-Unfortunately, horse-dealing lends itself more, perhaps, than most other callings to fraudulent practices. Why this should be so it 
is difficult to say, but nevertheless the fact exists. When the skin of the horse has been blemished or galled, different coloured hair makes its appearance on the seat of the injury, and it is no uncommon thing for the "horsecoper" to dye the offending hairs so as to enable them to escape detection. Such a fraud is a course easily discovered by the experienced man, but it is not so apparent to the novice. Then, again, sand cracks are often stopped with gutta-percha, although the coper more frequently relies on carefully plastered-in mud. Both these frauds can be detected if the hoof is 
thoroughly cleaned with a brush and water. Bishoping, so called after a man named Bishop, who first performed the nefarious operation, is a tampering with the teeth in order to make an aged horse appear more youthful. Some years ago this operation was very popular with a certain class of migratory dealer, but the strong arm of the law has done much to put a stop to it. Tar is sometimes given to broken-winded horses in order to keep quiet the secret-telling cough. There are scores of such tricks known to the stable hanger-on, but as they are also known to the expert they 


\section{A B C OF THE HORSE}

do not often accomplish their purpose. They are for the most part attempted at fairs, where the vendor relies for safety on the innocence of the purchaser, and upon his own capacity to make a speedy departure before the fraud is discovered. Needless to say, if attempted and discovered, the seller can promptly receive the attention of the police. It is only fair to the repositories, where so much business is done nowadays, to say that these frauds are but seldom attempted there, for if the auctioneer had his suspicions aroused, he would, for his own reputation's sake promptly inquire into the matter. 


\section{H A P T E R I I I}

HOW TO TELL THE AGE OF THE HORSE

THE teeth are the means by which the age of the horse can be told, and although there have been many cases in which they have misled the examiner, it may be safely stated that in 999 cases out of 1000, the teeth are up to eight years of age a sure indication of the age of the horse. In his highly interesting work, The Veterinary Manual for Horse Owners, Mr F. T. Barton, 64 
M.R.C.V.S. says : "The 'first,' 'second,' and 'third' molars (grinders) are but temporary, i.e., never replaced.

"On the other hand, all the incisor

(nipping) teeth are 'temporary', and it is their replacement, etc., which affords (aided in part by an inspection of the molars) such reliable evidence of the horse's age, at least, up to eight or ten years. After this time an opinion becomes more speculative. When the foal is one year old the 'fourth' permanent molar is up, but not worn, and at the age of two years the 'fifth' permanent molar is up. "The 'sixth' permanent molar is not E 
66

cut until the horse arrives at three and a half years.

"When the animal is two years and six months the 'first' and 'second' temporary molars are replaced, and the 'third' one at three and a half years.

"Up to two years or thereabout all the nipping (incisor) teeth are of a temporary nature. At three years the central permanent incisors are level, at four years the middle pair the same, and at five years the corners are on a level with the others. Many horses bred in the North of Scotland are frequently several months later in getting their teeth. 
"When the horse arrives at six years the corner teeth show wear, confined to their front edge, absent in a horse at five years.

"Seven and eight years afford the cheating horse-dealer the greatest delight.

"To many of these gentlemen all the horses they have for disposal are either seven or eight, and in one instance we remember examining the teeth of a pony, said to be seven, yet it proved to be thirty years old at least. "At seven years the 'Mark' is elongated, and it is very near the hinder edge. 
68 A B C OF THE HORSE

"Look at the corner teeth, in which the 'Mark' nearly runs the length of the tooth, but in a hcrse at 'eight' it is very much smaller. This also applies to the other incisors.

"At ten years a groove starts upon the outer face of the upper corner incisor.

"In all cases it is the rule to refer to the lower incisor teeth only, unless the mouth be kept closed."

The very simplicity of these directions forces the writer to make these extracts.

Sometimes when the mouth is closed the upper teeth project, overhanging 


$$
\text { A B C OF THE HORSE }
$$

the lower teeth, and this constitutes a "parrot mouth." A horse with such a defect is naturally placed at considerable disadvantage when feeding. Horses, like human beings, frequently suffer from diseases of the teeth, but in the majority of cases these troubles only arise during the early stage of their careers, or when old age is creeping on. The veterinary surgeon of to-day combines the duty of dentist with his other professional qualifications, and it is no uncommon thing for an animal to have the troublesome tooth extracted, or a surface filed down. 


\section{CHA PTER IV}

GENERAL MANAGEMENT: GROOMING -STABLING-FEEDING

THE one-horse owner seldom keeps a man only for the stable, as the work to be done would not be sufficient to occupy his whole time. He therefore generally fills in the odd hours by working in the house or in the garden. The chief requisites for a successful coachman are steadiness, sobriety, good temper, and a love of animals. The man who is hasty or brutal will soon 70 
ruin the best-tempered horse that ever ate out of a manger. No man should be expected to look after more than two horses and a carriage, if he has to go out with them. One of the disadvantages of keeping only one servant is that on wet days, if the mud is not cleaned off the carriage before it dries on, it takes longer to clean, and the paint and varnish suffer, whilst if the carriage receives the first attention the horse or horses run a risk of catching cold and developing that bane of the stable-cracked heels.

An excellent motto to be placed in every stable would be "Groom well 
and often." Lack of grooming is bound to mean lack of good health. Without it a sleek coat is impossible, and the respiratory system cannot be properly stimulated. Perspiration prevents the pores of the skin getting choked, but the fluid is apt to consolidate again at the roots of the hair if it is not removed, hence the necessity for good grooming. But how many men know the way to-or anyrate do -groom well? To say one in five would be probably too high an estimate. It is the curry comb which is so popular with the strapper, and when, by the aid of its sharp teeth, 
the animal has been sufficiently irritated to cause it to absolutely refuse to stand still, the brush is brought into use. If only the vigour with which it is applied could bear favourable comparison with that shown by the average groom in the way of hissing, for fear a speck of dust should find its way down his own throat, it would be all right, but unfortunately such is not the case. $\mathrm{He}$ hisses vigorously, brushes in a perfunctory way, the animal loses condition, and the master wonders why. Hard brushes are not necessary-a soft brush applied with pressure being 
quite as efficacious and less irritating to the skin than a hard one used with less pressure.

In his interesting and exhaustive work, The Practical Horse Keeper, Dr George Fleming, F.R.C.V.S., says: "Next in importance to food and water in stable-kept horses is grooming. There can he no doubt that the artificial state in which horses are kept renders cleanliness of the skin a necessity, and it is universally recognised that the beauty, health, and vigour of the horse are largely dependent upon the condition of his integument. 


\section{A B C OF THE HORSE}

"The function of the skin is very important, and just in proportion as that function is maintained in activity, so will the health be improved. To clean the skin thoroughly, a brush is, perhaps, the best appliance; though in Eastern countries, where the horses have very thin, sensitive skins and fine coats, as well as with some horses in our own country, a brush may cause considerable irritation. . . . It must, however, be regarded as essential to proper management that under no pretext is a horse to be left for the night until all his legs have been thoroughly dried. Nor is this precept very difficult of execution; 
a handful or two of light wood sawdust rubbed for a few minutes well into the hair will absorb all moisture from the most hirsute legs, affording not only a sense of comfort to the animal, but preventing those undesirable consequences engendered by continued application of cold and wet to the extremities. The iron curry comb should never, as a rule, be applied to the skin of horses. For long, rough coats nothing is better than a good dandy brush to remove dandriff, dust, and dirt; for finer-coated horses a good bristle brush suffices, and the use of this may be advantageously supple- 
mented by the wisp and rubber; indeed, for some extremely thin-skinned, finecoated horses, the two latter are generally found sufficient, provided the groom applies them energetically and efficiently. ... If the horse is heated, or is wet from perspiration or rain, he should on no account be allowed to remain undried for any length of time; but if he cannot be attended to immediately in a proper manner, he may either receive a temporary wisping of the body and legs, or clothing and bandaging these, or leaving on the saddle or harness until an opportunity arrives for grooming him; or, better still, he may 
78

be exercised for a short time, so as to prevent what is called a chill. When he can be attended to, the legs should be first well dried, and then bandaged, a blanket being thrown over the body meanwhile; when all the legs have been so treated, the body may then be groomed, and when this has been finished, if necessary, the bandages may be removed from the legs, and these thoroughly brushed out. It is very dangerous to allow the skin to dry by simple evaporation, and especially in a cold or draughty stable; as pleurisy, bronchitis, and inflammation of the lungs or intestines are very often the 


$$
\text { A B C OF THE HORSE }
$$

result. To groom a horse properly requires a considerable amount of time, and much skill and exertion; it is therefore necessary, unless grooms are very trustworthy, that owners of horses should know when their horses are groomed, and should also see that it is done thoroughly. A well-groomed horse gives evidence of the fact in the clean, shining, and healthy appearance of the coat, and if the hand be rubbed against the hairs it is not soiled by them. If, on the contrary, the horse is not well-groomed, the coat will be dull, staring, and unsightly, and patches of dirt may be seen upon it, while if the 
80

hand is pushed up through it, it will be covered with a white greasy film, and if the animal has perspired, scurf and dirt will be observed where the saddle or harness has been ; while on examination of the points of the hips and shoulders, the sides and points of the hocks, the roots of the hairs of the mane, tail, and forelock will yield further evidence. When the legs must be washed, which sometimes happens, as when very muddy, or with white and grey-legged horses, they should be thoroughly dried immediately after, and wrapped in flannel bandages. Some grooms are greatly in favour of washing 


\section{A B C OF THE HORSE 8I}

the body and legs, but unless in special cases-as when the skin is extremely greasy or dirty - this cannot be recommended. It is much better to wisp or scrape well, or both, and then clothe and bandage, if the body is wet, leaving the thorough cleaning to be carried out when circumstances are favourable. More especially should this procedure be observed in winter, in order to avoid what is known as 'mud fever.' If perfect drying could be ensured immediately after washing, perhaps no harm would result; but as this cannot always be relied upon, washing had better be dispensed with." 
82

Before leaving the subject of grooming, two pieces of advice to the novice: When your horse has been finished off for the day, occasionally visit the stable and pass your hand under the chest between the forelegs, and feel for hair matted with dry perspiration. If you find it once, forgive it, but if you find it a second time, dismiss the man. As a good housewife searches the corners of her house for dirt and dust, so the good horse owner-the man who recognises that he owes a duty to the animals who do his work for him - should examine those portions of their bodies which do not at the first glance attract 
attention. The second piece of advice is, occasionally run your fingers through the mane-see that it is not knottedand turn it over in order to make sure that the roots are not full of dust. It is another of those hidden corners which require the master's eye to investigate. Stabling.-It is easy to hold forth on the necessity of properly constructed and well - ventilated stables, but questions as to site, conformation and locality hardly come within the power or decision of the one-horse keeper if he be the tenant of the house he occupies. If a man lives in his own place he may be tempted 
84 A B C OF THE HORSE

to spend money on it, but if he is only the tenant he generally feels that he must make the best of what the landlord provides. But everyone can have a well-regulated stable. Nothing can be worse than for the horse to be exposed to a keen wind or a crossdraught when he is standing in his stall. Grooms are generally inclined, however, to go to the other extreme, and to block up every aperture. Excessive heat is almost worse for the animal than excessive cold, and the owner should watch carefully the thermometer, which should always find a place in every stable. When 


$$
\text { A B C OF THE HORSE }
$$

the doors are thrown open the first thing in the morning, the nostrils are often assailed by a strong odour generated by stale litter, and lack of proper ventilation. How can any animal, coming out of such a place, be expected to be refreshed by its night's rest? The horse wants pure air as much as man. The owner should see that, whilst all causes of draughts are stopped up, the ordinary precautions for the maintenance of proper ventilation are preserved. I cannot urge this point too strongly, for I have often seen in young animals the vitiating effect that a fotid atmosphere 
86

has had. It is not the same night's evacuations which do so much mischief as those of previous days. In too many stables the upper surface of the litter is kept all right, but it is the foundation of the bed which reeks of ammonia, which sends up its fumes into the animal's nostrils and eyes, and sets up irritation and disease. Occasionally take a fork and turn over the bed, and see that its foundation is clean. It is not much to do; one turn with the fork is sufficient to get a general impression, and the groom seeing you do it once will probably, from mere expectancy of your renewing your investigations, 


$$
\text { A B C OF THE HORSE }
$$

see that the bed is kept all right. There are some people who always insist upon the doors of their stables being kept closed when the horses are out. They do so on the score of neatness, but doors thrown wide open-back against the wall - are equally as neat, and better from a hygienic point of view, because the stable can thus be thoroughly aired; the sun's rays have then a chance of finding their way into the little nooks and corners which are such happy hunting grounds for all forms of bacteria. Light is the enemy of the microbe, and therefore let there be light. 
Cleanliness is of the utmost importance in any stable, and with cleanliness naturally goes attention to all matters of drainage. Do not allow the dung-heap to be made just outside the stable door. It is easier to throw the used-up straw there, but it will also be in just the position to pollute the atmosphere, and to cause the smells arising from it, when the wind is in a certain direction, to flow back into the stable. Be the system of drainage what it may, the owner can at anyrate see that the drains are not allowed to collect and stagnate in any little holes that there may be in the floor, and 
that after the brush has been passed along the back of the horses' stalls, a little disinfecting fluid, or, better still, powder, is thrown down. All these things require a master's eye. It is the little details of stable management which make for success, and however keen a groom may be, the knowledge that the "guv'ner takes a pride in his horses" should always be behind him. Feeding.-The question of food is of as great importance as any. The horse requires as much attention in the matter of diet as a human being, and this is what too many men fail to realise. They give to an animal 
his proportion of food, and then they think they have done their duty. But such is not the case. Some horses are as fastidious as any man. They want to be tempted to eat, and the mess which is thrown into their stall does not induce an appetite. If they are at all of a nervous temperament can they be expected to go on with their repast whilst a man is hissing around them with a sharp curry-comb, and because they venture to move yells, "Get up, you brute!" Good oats build up strength, and not to give them is false economy. The well-fed animal is capable of doing better work 
and the extra cost of the oats consumed is repaid by the work done. The horse looks for his food at certain stated times. He knows as well as any human being when those times arrive, and if he is disappointed his stomach gets weak. He cannot tell it, and man should therefore remember it for him. Neither can the horse protest, except by allowing the cravings of hunger to go unsatisfied, when his manger is full of stale or dusty food. A clean and sweet-smelling manger tempts the appetite, and good food is easily spoilt by mixing it with refuse from a previous meal. 
Bran mashes should be given regularly once a week, and if the coat is at all inclined to harshness, some linseed made into a hot mash will have a beneficial effect. Some stablemen are very fond of limiting the supply of water. This is a great mistake, as unless the horse comes home very hot, he is not likely to drink more than is good for him. $\mathrm{He}$ is far more likely to injure himself if not allowed to quench his thirst, or if permitted to do so freely after a lengthy and enforced abstinence.

In his highly interesting and valuable work, Horses and Stables, Lieutenant- 
General Sir F. Fitzwygram, Bart., says: "Of the quantity of water to be given at one time, the horse himself is in general the best judge. Excepting in a few cases, such as where the horse is excessively hot or exhausted, or has from any cause been kept without water for an undue length of time, or where there is a tendency to purgation or diuresis, the horse may safely be allowed to drink as much as he likes. It is a cardinal rule in stable management that horses should be watered before being fed. The contrary practice is exceedingly likely to cause colic, otherwise called gripes. ... It is a 
94

A B C OF THE HORSE

somewhat singular fact that horses may be watered with safety almost immediatety after their return from work, even though somewhat heated. Probably the friction from grooming, which takes place about the same time, prevents the occurrence of a chill. Many regiments water their horses on their way home from a field day, if a river or troughs are handy, and it is certain that no mischief results from the practice. Probably in this case the further slight exercise in returning home prevents mischief. There is less risk of chill from drinking cold water when the body is still actively warm 


$$
\text { A B C OF THE HORSE }
$$

than when the system has begun to flag. If, however, the horse is thoroughly tired and fagged, the water should be made slightly tepid, or a bucket of warm gruel may be given instead. In such cases there may not be sufficient vitality to raise a large quantity of cold water to the temperature of the body; and hence the animal may become chilled, and his coat will stare, his bowels may become deranged and further serious consequences may result." 


\section{CHAPTER V}

\section{MINOR ACCIDENTS AND AILMENTS, AND THEIR TREATMENT}

IN this chapter merely a few of the minor accidents and ailments which occur to the horse are dealt with, for it would be impossible in the space at disposal to deal lengthily with the subject. Whenever a horse is found to be really ill, the best plan is to at once call in a veterinary surgeon. It is not fair to the animal for the owner to try amateur doctoring, for there are many diseases which 96 
to the inexperienced eye present the same symptoms, although the methods of successful treatment are bound to be different.

\section{Bleeding (See Hæmorrhage).}

Blood Spavin.-This is an ignorant expression, for it refers to what is really a varicose vein, as it passes over the front of the hock.

Broken Wind is displayed by difficulty of breathing. An examination of the flank will show a hesitancy during the expulsion of each breath, although inspiration is performed with steadiness. A permanent cure is impossible, although careful atten- 
98 A B C OF THE HORSE

tion to feeding will bring about some alleviation of the trouble. Feed and water frequently and in small quantities is sound advice.

Bruises.-The limbs of the horse are most frequently bruised. Hot fomentations followed by a cooling lotion will have a soothing and beneficial effect.

Canker.-Really an advanced stage of thrush, and is due to improper stable management. Violent inflammation is always present, and the odour emitted is overpowering. When suspected, skilled aid should at once be called in.

Capped Elbow.-Generally caused by 


\section{A B C OF THE HORSE}

the animal striking that joint when lying down, the continual irritation eventually producing a tumour.

Capped Hock.-Animals which are given to kicking frequently get their hocks capped. If the trouble is of recent date it will be shown by increased heat in the part.

Catarrh or Cold.-This is a common disease. Discharge from the nasal organs is usually accompanied by some fever and cough. Careful nursing is chiefly required. Draughts must be avoided, although there should be plenty of fresh air. Laxative food and a little nitrate of potass in the water 
100

$$
\text { A B C OF THE HORSE }
$$

will usually effect a cure. Should the symptoms become grave then skilled aid should be at once called in.

Corns.-The inner quarter of the sole is the seat of a corn, and the fore limbs are those usually affected. They are the result of the unnatural pressure thrown upon the part by the use of the shoe. The remedy is to be found in removing the pressure by paring away the horn covering the seat of the corn, and thus preventing the shoe from touching it.

Cracked Heels.-Easily recognised by the swelling-up of the legs, and the amount of heat in the neighbourhood of 
the heels. The skin is hard, glossy and red, and fissures and discharge follow. The treatment consists of fomentations of hot water and the application of poultices made of linseed, or of equal parts of linseed and bran. Later on, when all heat has disappeared, an ointment consisting of powdered alum and common lard should be rubbed in.

Curb.-An enlargement at the back of, and just below, the point of the hock. Sickle-shaped hocks are predisposed towards curbs.

Eczema is a skin disease which it is often hard to cure. Skilled aid should be obtained. 
Elephantiasis.-A permanent thickening of the skin and underlying tissues, causing a permanent enlargement of the part affected. Attacks of what is vulgarly known as "Monday Morning Disease," bring it on. That disease is most frequently met with in animals employed in slow work, and who remain in the stable from Saturday to Monday.

Flat Feet are highly objectionable as they are a sign of weakness.

Fistulous Withers.-A difficult disease to cure. It is highly dangerous to work a horse suffering from them, as sudden pressure on the part affected might 
cause it to bolt or become unmanageable.

Glanders. - This terrible disease is almost entirely confined to the large towns. Scientific research has thrown some light upon its ravages, but unfortunately its cure up to the present seems hopeless, whilst the infectious powers of glanders are known too well. Human being and animal alike are endangered by the presence of a glandered animal. "Glanders," says Captain Hayes in Veterinary Notes, "is most readily communicated by inoculation with the diseased discharge from the nostrils, the mere contact of 
which with any of the mucous membranes is sufficient to give rise to the disease. Hence it is advisable, when examining a suspected horse, to be very careful to avoid the possibility of his sneezing or coughing in one's face, which we may do by using the special face-guards that are manufactured by veterinary instrument makers for the protection of persons examining glandered horses. Babès has proved that the glanders bacillus may penetrate into the skin, without the aid of any existing wound, by gaining entrance into some of the hair follicles, where it will multiply, cause ulceration of the skin, and thus 


\section{A B C OF THE HORSE \\ 105}

infect the animal. The moral is obvious. Inoculation with glanderstainted blood has been found to fail more often than it succeeds in transmitting the disease... This power of infecting the atmosphere of a stable seems to be possessed by glandered animals which show no outward symptom of the disease, as well as those which have a running from the nose. In fact it has not infrequently happened that such horses have, without contact, infected healthy animals, into whose near vicinity they have been brought, so virulently that the latter have died in a short time from glanders, though the 
106

former continued in apparent health." Describing the symptoms of acute glanders, a form of the disease which is of course the most easily diagnosed, Captain Hayes says: "More or less persistent shivering fits; a marked rise (often of $7^{\circ}$ or $8^{\circ} \mathrm{Fahr}$.) in the internal temperature of the body (normal, about $99^{\circ}$ Fahr.), and, consequently, more or less fever usher in the attack. The coat is dry and staring; the pulse frequent and weak; the breathing hurried and painful; the animal rapidly loses condition; and the mucous membranes of the nose become filled with nodules and ulcers which run together 


$$
\text { A B C OF THE HORSE }
$$

and discharge pus. Symptoms of farcy, diarrhœa and swellings of the limbs and head may appear." The premonitory shivering fits and rise of temperature should, however, at an early period of the disease serve as a warning to the amateur of the necessity of at once obtaining professional aid.

Grease.-This is an aggravated form of sore heels. If not taken in time the disease extends above the fetlock-joints, and there is considerable swelling, with cracks and ulcers in the skin, and a discharge of offensive matter. The disease is frequently the result of overcrowding and injudicious feeding. It is admitted 
always to be the result of improper stable management. Fomentations and poultices should be the first treatment adopted.

Gripes.-This is the popular name for colic, and may arise from a number of causes. The pain comes on suddenly, the horse paws, strikes at its belly, lies down, rolls, or remains outstretched. The attacks are short and sharp. Turpentine in linseed oil is an old-fashioned and popular remedy, but most grooms have their own favourite medicine for the disease. Some horses are very subject to colic, and if this is found to be the case a veterinary 
surgeon should be consulted as to the probable cause, which may be found to be indigestion.

Hamorrhage or Bleeding.-Sometimes pressure will stop this, or plugging the wound with tow. Cold water will frequently stop bleeding if only small vessels are involved. Water heated to $130^{\circ}$ Fahr. continually applied is a safe remedy, but failing success a styptic must be used. When this becomes necessary it is well to call in a veterinary surgeon, as extensive bleeding necessarily denotes injury to one of the larger vessels.

Inflammation.-This state may of 
I IO A B C OF THE HORSE

course be set up in any portion of the body. It is denoted by increase in temperature, or by heat of the part, if it be a local affection. When inflammation of any of the internal organs is suspected, skilled aid should at once be requisitioned, as the progress of such diseases as inflammation of the lungs or bowels is rapid and needs prompt and skilful treatment.

Influenza.-The remarks with regard to inflammation are especially applicable to influenza, which commences with a shivering fit, and if neglected is succeeded by symptoms of high fever. The progress of the disease is very rapid. 
Laminitis is chiefly confined to the sensitive laminæ. The hoofs get very hot, and if tapped with a hammer the pain is intensified. The horse adopts a cramped attitude whilst standing, and the bodily health is soon affected. Laminitis frequently leaves permanent injury to the hoof, it being no uncommon thing for it to be shed.

\section{Lungs.-(See Inflammation.)}

Mange-A contagious disease causing the hair to fall off in patches, leaving the skin scaly and rough, and greasy to the touch. There are several excellent specifics on the market. The local remedy may consist of sulphur 
I I 2 A B C OF THE HORSE

ointment, made up of sulphur and train oil in equal quantities and applied to the affected parts.

Medicines, and How to Administer Them.-The most popular form of giving medicine to the horse is by means of a ball. In giving a ball the horse's tongue is drawn out of his mouth on the off-side and held there firmly in the left hand. The ball which is held between the fingers and thumb of the right hand is then placed well back and down the throat of the animal. The tongue is then released and the head is held up until the medicine is seen to pass down the 
gullet on the left side of the neck. The operation should be performed as quietly as possible, and if the animal is at all refractory it is better to obtain the aid of a skilled person. On no account should the hold on the tongue be retained if the animal struggles violently, as otherwise serious injury is likely to result. In giving a drench the tongue should not be interfered with. The horse's head should be raised so that the nose is a little higher than the horizontal line. To quote again from Dr Fleming's Practical Horse Keeper: "This may be done, if the horse is quiet, by an assistant; but if he is 
restless it is necessary to keep the head elevated by a loop of cord inserted into the mouth over the upper jaw, the prong of a stable fork being passed through it, and the handle steadily held by the assistant. The drink is then to be given by a person standing on the right side (the assistant being in front or on the left side of the horse) the side of the mouth being pulled out a little to form a sack or funnel, into which the medicine is poured, a little at a time, allowing an interval now and again for the horse to swallow. If any of the fluid gets into the windpipe (which it is likely to do if the head is 
held too high), coughing will be set up, when the head should be instantly lowered. Neither the tongue nor the nostrils should be interfered with.

"Powders may be given in a little mash or gruel, well stirred up."

Megrims come on quite suddenly. Heart disease is believed to be one of the chief causes of what is really congestion of the brain. A tightfitting collar or long exposure to the rays of a powerful sun contributes to the appearance of the disease. A first attack predisposes to a recurrence.

Mud Fever. - An eruption upon the legs, belly, etc. This is the same 
condition of the skin as cracked heels, and is due to the same cause or causes.

Navicular Disease.-The seat of this disease is the back part of the foot, where the navicular bone is to be found. The animal affected goes downhill with more difficulty than he goes uphill. A cure is impossible.

Nursing during Sickness. - Careful nursing is half the battle during sickness. Fresh air, quiet and cleanliness are absolute essentials. The stable should be warm without being stuffy. The appetite should be tempted by continually changing the food offered. 


\section{A B C OF THE HORSE}

The body should not be overloaded with heavy clothing.

Poultices are made of bran,

linseed meal, turnips, carrots or charcoal. They should be encased in some waterproof material. When they are to be applied to the feet a poulticeshoe is of advantage.

Quittor. - Frequently the result of a puncture of the foot when shoeing, or of a tread on the foot. It is a difficult disease to cure.

Roaring.-An animal suffering from this disease is of little value. It is noticeable during inspiration of breath when the horse is in motion. 
Sandcrack.-A splitting in the wall of the hoof.

Shivering. - An incurable malady shown by a quivering of the muscles in the region of the shoulders, hind quarters and tail.

Sprains.-In all cases of sprains it is necessary to keep the affected part as still as possible. The preliminary treatment should consist of cold-water bandages. Absolute rest is an essential to recovery.

Stringhalt.-An involuntary uplifting in "a jerky manner" of one or both the hind limbs during movement. 
Thoroughpins are generally seen in short fleshy hocks, and are a distention of the back parts of the hocks. They are compressible on both sides of the hock, and are often the results of hard work.

\section{Thrush.-Is an ulceration of the frog,} causing a secretion of very offensive matter. The disease should on no account be neglected.

Warts.-Appear on different parts of the skin. They may be removed by caustics, ligature, the hot iron or by the knife.

Weaving. - There is no cure for this habit, which consists of a restless 
moving of the head from side to side. Horses which contract the habit are usually bad "doers."

"Whistlers."-A popular term for an affection of the breathing organs. It constitutes unsoundness. Wind Galls.-Puffy swellings in the neighbourhood of the fetlocks. They are most frequently met with in animals who have done a great deal of work.

Worms.-Several kinds of worms infest the intestines of the horse, and they all have the effect of producing loss of condition. When a voracious appetite is noticed and a harsh, rough skin, 
their presence should be suspected. There are many excellent worm medicines on the market, and any chemist will supply one.

Wounds.-When there is extensive bleeding from a wound it should be stopped as speedily as possible, as loss of blood means loss of strength. In his Veterinary Manual, Mr Barton, M.R.C.V.S., says: "If an artery has been torn, the blood is sent out in 'jets,' as it were, whereas bleeding from veins is 'continuous,' and less serious than the former, being impure blood and of a purple colour. Pressure by the finger can often be 
used to control bleeding, a fact to be remembered in cases of emergency. If the bleeding vessel can be grasped. it may be tied off with a piece of catgut or silk thread, etc. The free use of cold water will often stop the bleeding and should always be tried; besides, it helps to clean the wound. The application of tincture of steel, Friar's Balsam, styptic, collodion, alum, etc., is used for the same purpose when the bleeding is not excessive." 


\section{NATURAL HISTORY WORKS}

\section{A YEAR WITH NATURE}

By W. Percival Westell. Illustrated with Photographs from Nature and Still Life, by J. T. Newman, G. Watmough Webster, H. Stone, and from Drawings by the Author. Over 170 Illustrations. Royal 8vo, cloth extra, gilt, $296 \mathrm{pp}$. Price ros. $6 \mathrm{~d}$.

"This is a very charming book. . . Their pictures of bird life are the most beautiful that have ever been produced as book illustrations; and they alone are more than good value for the modest ros. $6 \mathrm{~d}$. at which this handsome volume is issued.... This pleasantly written and excellently printed book, which possesses alike great artistic merit and educational value." - The Illustrated Sporting and Dramatic News.

\section{. By the Same Author .}

\section{A HANDBOOK OF BRITISH BREEDING BIRDS}

Containing a complete description of all birds known to breed in the British Isles-(I) When and where their nests are built ; (2) What they are composed of ; (3) The number and colour of their eggs ; (4) Their food; (5) Nature of their voices, etc.; and (6) some local and old-fashioned names.

Profusely Illustrated. $188 \mathrm{pp}$. Cloth, 6d.; Leather, 1s. "This popular little book."-Morning Post.

"An unpretentious but interesting little work."-Westminster Gazette. "Will be very welcome to all lovers of British birds."-People. "Gives a large amount of useful information."-Land and Water.

\section{IMY CANARY BOOK}

Contains Chapters on the Choice of a Bird, Varieties, Cages, Management, Diseases, Breeding, Mules, etc. By James S. Gould. Price is.

"Is written for those who keep a Canary, and to those we have pleasure in recommending it, and can assure them they will find numerous useful hints in it."-Poultry. 


\section{BIOGRAPHY AND HISTORY}

MISS MARIE CORELLI. By Kent CARR. An Edition. de-luxe, printed on crown $8 \mathrm{vo}$, superior antique wove paper, to range in size with the Works of this Popular Writer. Illustrated with large, specially taken pictures. Price 5s. nett. Edition limited to 500 copies-each copy being numbered.

Price 5s. nett.-HANDSOME PRESENT

\section{SIR HENRY IRVING AND MISS ELLEN TERRY:} A Record of over 20 years at the Lyceum Theatre. By iValter Calv́ert. With 76 choice Illustrations. Edition limited to 300 copies and cannot be reproduced-each copy numbered. Only a few left.

\section{COWPER AND MARY UNWIN. By CAROLINE} Grarey, author of "Three Empresses," "Two French Queens," "Royal Friendships," "Rural Life," etc. Large crown 8vo, cloth. Price 6s.

A Centenary Study by the author of "Three Empresses," in which she relates the love story of Cowper and Mary Unwin in an interesting and attractive manner.

"A good book on such a subject is always welcome."-Literary World.

"An admirable account of the poet... we cordially commend Mrs Gearey's volume to the attention of Cowper's admirers."-Morning Post.

"Brings together with sympathy and discernment the story of Cowper's shadowed life and Mary Unwin's unselfish devotion."-The Standard.

"The book is a delightful one. ... This quietly interesting volume."The Academy.

"The book is exceedingly readable throughout."-Westminster Gazettc.

"The course of the poet's life, and his connection with Mary Unwin, are traced with loving care and accuracy."-The Queen.

SIR WALTER'S WIFE. By EMILy Richings. An Historical Romance. Illustrated with Portraits of Sir Walter and Lady Raleigh. Large crown 8vo, cloth. Price 6s.

"Of exceeding interest."-Saturday Review.

"Admirable and evidently trustworthy."-Pall Mall Gazette.

"A romance of marvellous interest."-Dirmingham Daily Post. 


\section{THE POETIGAL WORKS}

\section{. OF . . \\ ELLA WHEELER WILCOX}

TASTEFULLY BOUND IN BLUE AND WHITE COVERS

Royal 16mo. Price is. each.

1. POEMS OF PASSION. 6oth Thousand.

2. POEMS OF PLEASURE. 25th Thousand.

3. MAURINE AND OTHER POEMS. 5th Thousand.

4. POEMS OF LIFE. (A companion volume to "Poems of Passion.")

Also uniform with the above volumes

5. THE LOVE LETTERS OF A VAGABOND. By E. Heron-Allen. A small volume of spirited Poems.

\section{PICTURES WORTH FRAMING Price 3s. 6d. Complete in Wrapper.}

HUNTING NOTIONS. By Henry Alken. A set of Six famous Pictures by this celebrated artist. Beautifully printed in colours from carefully engraved Wood Blocks.

HUNTING NOTIONS. Second Series. By Henry Alken. A set of Six more famous Pictures, in same style as above. 


\section{BIJOU BIOGRAPHIES}

\section{Price 6d. and Is. each}

\section{Authoritatively Written. Well Printed. Substantially Bound (in Cloth) with Special Portraits}

THE volumes are, as the name of the series indicates, small. It is possible to carry them in the jacket pocket without the slightest inconvenience.

They are, in printing, paper and binding, equal in quality to any half-crown volume on the market.

\section{What the Press says the Bijous are:-}

"In an age when 'extracts,' 'essences' and 'tabloids' are so much in favour, such highly-compressed literature will no doubt be popular."Morning Post.

"These little books are interesting, informative and cleverly written ... deserve much more than a success de curiosité. . . . Got up very prettily, quite wonderfully so, in binding, paper and type. A collection on a bookshelf would have a very attractive appearance." - Saturday Reviezu.

"Concisely written, clearly printed, and give just the facts that busy people are anxious to know."-Lloyd's News.

"They are compact in form and full of information, tersely and lucidly given."-Sunday Sun.

"Such comprehensive little books of reference, besides being very interesting, are perfect boons to all." - The Lady.

"Delightfully dainty little volumes for sixpence."-Lady's Pictorial.

"There is no denying that the publisher has got them up very prettily." -The Speaker.

"Daintily bound and printed, these concise and well-written little volumes are pleasant to read."-Glasgoze Daily Mail.

"In each case the biographer has done his work we :"-Western Morning Nerus. 


\section{THE BIJOU BIOGRAPHIES}

\section{PRICE 6d. EACH}

1. THE RT. HON. JOSEPH CHAMBERLAIN, M.P.

By ARTHuR WALlace.

The Sunday Sun commends it " to the Anglophobe at bome and abroad."

2. LORD KITCHENER. By W. Francis Aitken.

"A bright, lively book," says Lloyd's.

3. LORD ROBERTS. By ERNEST Russeli.

"Deserves to be called brilliant," according to the Glasgow Daily Mail.

4. MR JOHN BURNS, M.P. By G. H. KNott.

"By no means the least interesting of The Bijou Biographies." -Lloyd's.

5. LORD Salisbury. By Edward Salmon.

6. DR W. G. GRACE. By Acton IVye.

\section{PRICE 1s. EACH}

7. HIS MAJESTY KING EDWARD VIIth. Harry Whates. Double Volume.

8. Miss MARIE CoRELli. By Kent Carr. Double Volume.

9. LORD KELVIN. By J. Munro. Double Volume. 


\section{THE GLOBE STAMP ALBUM}

Strongly bound in Padded Cloth and well guarded. $25^{6}$ pages. Price 35 .

This Album contains spaces for about 6000 stamps, is illustrated throughout with facsimiles of stamps, reproduced by Special Permission, and will be found thoroughly up-to-date in every respect.

\section{MY BOOK OF CONFESSIONS}

An Illustrated Album, for collecting the opinions of friends, containing many new up-to-date questions. I60 pages, 4 to.

\section{MY BOOK OF AUTOGRAPHS 20}

An Album for collecting the Autographs of friends, etc., and containing facsimiles of the Autographs of many celebrities; a Register of "At Home" Days will be found at the end of the book. I6o pages, 4 to.

The above two books are printed on tinted paper and bound in the following styles:-

Padded Cloth, Gilt Lettered, Gilt Edges, - - - - 3s. Paste Grain, Gilt Lettered, Gilt Edges, Round Corners, - 5s. Paste Grain, Padded Sides, Gilt Lettered, Gilt Edges,

Round Corners, - _ - _ - - - 6 s.

\section{A SERIES OF OVER 50 DIFFERENT BIRTHDAY BOOKS, AUTOGRAPH, CONFESSION and STAMP ALBUMS, \\ ETC.}

Stocked in Cloth and various styles of Leather Binding. (See separate Catalogue.)

Admitted to be the best value in the market, and to comprise the most varied assortment. Supplied on liberal terms. 

